\section{Comparative Effect of Calcium Mesoporous Silica Versus Calcium and/or Fluoride Products Against Dental Erosion}

Fernanda Michel Tavares Canto ${ }^{1}{ }^{\oplus}$, Adilis Kalina Alexandria ${ }^{1,2}{ }^{\oplus}$, Thiago Isidro

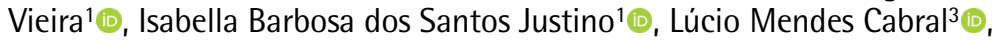
Raphael Ferreira da Silva ${ }^{3}{ }^{-}$, Lucianne Cople Maia' ${ }^{1}$

\begin{abstract}
The aim of this study was to compare the effects of a single application of a new calcium mesoporous silica nanoparticle ( $\mathrm{Ca}^{2+}-\mathrm{MSN}$ ) versus other calcium and/or fluoride products against dental erosion. Enamel blocks were half-covered and assigned to six groups ( $\mathrm{n}=$ 10): $\mathrm{Ca}^{2+}-\mathrm{MSN}$; casein phosphopeptide-amorphous calcium phosphate mousse (CPPACP); CPP-ACP/F- (900 ppm F-); titanium tetrafluoride $\left(\mathrm{TiF}_{4} 1 \%\right)$; sodium fluoride ( $\mathrm{NaF}$ 1.36\%); and Milli- $Q^{\circledR}$ water (negative control). A single application for each product was completed on the exposed areas of the blocks and were submitted to an erosive challenge. Differences in volumetric roughness (Sa), and tooth structure loss (TSL) by use of three-dimensional noncontact optical profilometry were evaluate. Scanning electron microscopy (SEM) was performed. Analysis of variance and Tukey's test for Sa and the Kruskal-Wallis and Mann-Whitney U tests $(p<0.05)$ for TSL, respectively. Results: When evaluating $\mathrm{Sa}$, all products presented differences in roughness when compared with the control group $(p<0.05)$ but not with each other $(p>0.05)$. However, when analyzing the $\mathrm{TSL}_{1}$ it was observed that $\mathrm{Ca}^{2+}-\mathrm{MSNs}_{1} \mathrm{TiF}_{4}$ and $\mathrm{NaF}$ were more effective in preventing dental erosion versus CPP-ACP, CPP-ACP/F-, and Milli- ${ }^{\circledR}$ water $(p<0.05)$. In the SEM images, the negative control presented the worst loss of dental structure, with more porous enamel. $\mathrm{Ca}^{2+}-\mathrm{MSN}$ s were as effective as $\mathrm{TiF}_{4}$ and $\mathrm{NaF}$ to reduce the tooth structure loss.
\end{abstract}

\author{
'Department of Pediatric Dentistry \\ and Orthodontics, UFRJ - \\ Universidade Federal do Rio de \\ Janeiro, Rio de Janeiro, RJ, Brazil \\ ${ }^{2}$ Department of Preventive and \\ Community Dentistry, UERJ - \\ Universidade do Estado do Rio de \\ Janeiro, Rio de Janeiro, RJ, Brazil \\ ${ }^{3}$ Department of Drugs and \\ Medicines, School of Pharmacy, \\ UFRJ - Universidade Federal do Rio \\ de Janeiro, Rio de Janeiro, RJ, Brazil
}

Correspondence: Lucianne Cople Maia, Rua Rodolpho Paulo Rocco, 325, Cidade Universitária, 21941913 Rio de Janeiro, RJ, Brasil. Tel/Fax: +55-21-3938-2098. e-mail: rorefa@terra.com.br

Key Words: tooth Erosion, nanoparticles, fluoride compounds.

\section{Introduction}

When dental tissue is exposed to an acid attack without microbiological interference, an irreversible, chronic, localized, pathological, and painless loss of enamel, defined as dental erosion, occurs (1). The significant increase in the consumption of foods and beverages with a high degree of acidity can contribute to the loss of dental structure and an erosive lesion occurs (2). Extrinsic acids are related to the occurrence of dental erosion due to a change in the dietary habits of the population (3). The acid attacks induce a softening of the dental surface and, gradually, the enamel is diluted (prismatic and interprismatic enamel) (4).

Changes in eating habits and improvements in oral hygiene, together with the most frequent exposure to fluoride compounds, act as preventive agents against tooth erosion (5). Regular use of fluoride prompts the formation of calcium fluoride, which presents a lower degree of dissolution as compared with hydroxyapatite (6). In this sense, fluoride products have been studied as potential preventive and therapeutic agents to address the dental demineralization that occurs during dental erosion (7). In addition, in the literature, the use of novel calcium-based compounds, both in association or not with fluoride, has been proposed in an effort to reduce mineral loss (8).
Nanoscale compounds such as mesoporous silica can provide chemical and physical improvements in the treatment of enamel or dentin demineralized in relation to micrometric compounds, including greater mechanical and thermal stability, higher heat resistance, and lower dissolution (9). Furthermore, the combination of two or more substances in the form of nanoparticles generally results in the creation of a product with properties superior to those observed in the original separate substances (10).

The aim of the present study was therefore to compare the effects of a single application of a new calcium mesoporous silica nanoparticle ( $\mathrm{Ca}^{2+}-\mathrm{MSN}$ ) versus ordinary calcium and/or fluoride products against dental erosion.

The null hypothesis of this study was that a single application of calcium mesoporous silica nanoparticles does not reduce volumetric roughness (Sa) and tooth structure loss (TSL) after erosive challenge in comparison with products that are commonly used in dental practice.

\section{Materials and Methods}

Since in the present study the authors used similar compounds as Alexandria et al. (2017)11 in which the TSL (value \pm standard deviation) for the negative control and CPP-ACP groups was $44.17 \pm 8.55 \mu \mathrm{m}$ and $31.12 \pm 4.73$ 
$\mu m$, respectively, these values were assumed for the sample size calculation considering a power of $80 \%$ and $\alpha=5 \%$ for 6 groups (BioEstat 5.3; Instituto de Desenvolvimento Sustentável Mamirauá, Tefé, Amazonas, Brazil). A calculated sample size of $\mathrm{N}=08$ to be allocated into each group of treatment was required to complete the study. With the estimative of $25 \%$ of lost, at least $\mathrm{N}=10$ enamel blocks for each group should be select.

Six groups containing 10 bovine enamel blocks each were treated with either the Ca2-MSNs; casein phosphopeptide-amorphous calcium phosphate (CPP-ACP) mousse (GC Corp., Tokyo, Japan; Brand Data: 161102B); CPPACP/F- mousse (CPP-ACP + 900 ppm F- from GC Corp., Tokyo, Japan; Brand Data: 170110A); titanium tetrafluoride $\left(\mathrm{TiF}_{4} 1 \%\right)$; sodium fluoride (NaF 1.36\%); or Milli- ${ }^{\circledR}$ water (MilliporeSigma, Burlington, MA, USA) as a negative control, respectively. After treatment, the blocks were exposed to in vitro erosive challenges and the topography of the blocks was analyzed by using three-dimensional (3D) noncontact optical profilometry and scanning electronic microscopy.

\section{Sample Preparation}

Sixty enamel blocks measuring $4 \mathrm{~mm} \times 4 \mathrm{~mm} \times 2 \mathrm{~mm}$ were obtained from the vestibular face of the bovine incisor with the aid of a diamond disk mounted on an automatic cutter (Isomet ${ }^{\circledR}$; Buehler, Lake Bluff, IL, USA) (Fig. 1A).
Teeth without white spots, cracks, or any alterations readily observed were included. The enamel surfaces of the blocks were sequentially polished using water-cooled silicon carbide paper of sizes 600 and 1,200 (Extec Corp., Enfield, CT, USA), respectively (Fig. 1B). To select the enamel blocks, the initial microhardness value of each was calculated as a mean value of five indentations per the protocol of a previous study using a Knoop diamond-tip microdurometer (Bühler ${ }^{\circledR}$ Micromet ${ }^{\circledR}$ 5104; Mitutoyo Corp., Tokyo, Japan), with a static load of $50 \mathrm{~g}$ applied for $5 \mathrm{~s}$ (12). Blocks with IMH values of $10 \%$ above or below the mean values were discarded (Fig. 1C). An evaluation of the final microhardness (after the erosive challenge) was not performed because this measure could mask the real mineral surface loss (5), since, after the erosion, the removal of the superficial layers was performed, being more indicated the use of profilometry analysis (11).

After the blocks were selected, half of each block (designated as the untreated area) was covered with nail varnish protection (L'Oreal, Clichy, France) (Fig. 1D). The blocks were identified by codes, with the objective of guaranteeing adequate blinding of the experiment.

\section{Treatments and Erosive Challenge}

The blocks $(n=60)$ were randomly allocated by way of a lottery, following the principle of randomness, and were

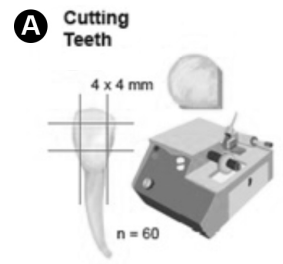

B Grindin

E

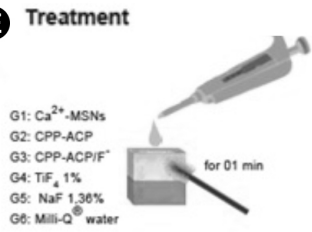

(H) Nail Protection Removal

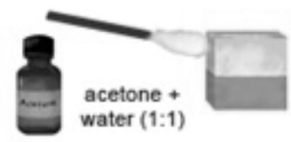

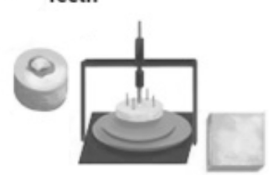

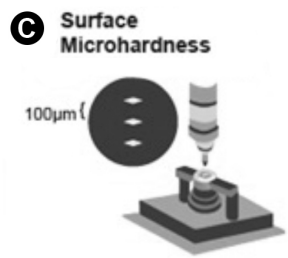

(D) Nail Protection

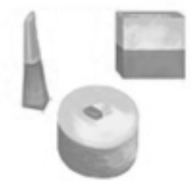

F Cleaning

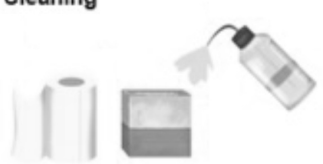

G Erosive Cycling

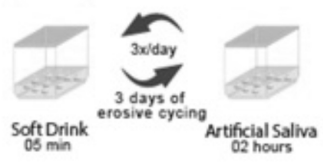

J MEV

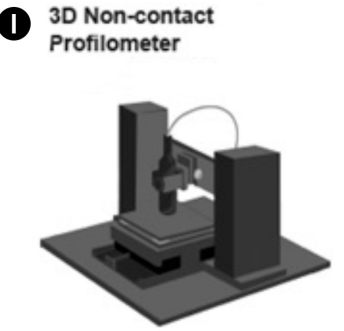

Figure 1: Schematic drawing of methodological steps.A) Cutting Teeth; B) Grinding Teeth; C) Surface Microhardness; D) Nail Protection; E) Treatments; F) Cleaning; G) Erosive Cycling; H) Nail Protection Removal; I) 3D non contact Profilometer; J) MEV. 
divided into six groups according to the proposed surface treatments ( $n=10$ each group), as follows:

Experimental $\mathrm{Ca}^{2+}-\mathrm{MSNs}$; CPP-ACP mousse; CPP-ACP/ F- mousse; $\mathrm{TiF}_{4} 1 \%$; NaF 1.36\%; Milli- ${ }^{\circledR}$ water (as the negative control).

The $\mathrm{Ca}^{2+}-\mathrm{MSN}_{1} \mathrm{TiF}_{4}$, and $\mathrm{NaF}$ solutions were prepared as a solution in the Laboratory of Industrial Pharmaceutical Technology (Federal University of Rio de Janeiro, Rio de Janeiro, Brazil). The CPP-ACP and CPP-ACP/F- products are commercially available as toothpastes, so a 1:3 slurry solution was prepared composed of toothpaste (one-third) and distilled and deionized water (two-thirds; Milli- ${ }^{\circledR}{ }^{\circledR}$.

Using a pipette, $100 \mu \mathrm{l}$ of each product was distributed on the surface of the respective enamel blocks. At one minute after application, the product residues were washed off, and this was followed up with drying using absorbent paper. A single researcher proceeded with the application of the products (Figs. 1E and 1F).

The erosive challenge was promoted by immersing the blocks in two solutions: a low-pH solution (2.58) to simulate an erosion condition and a neutral-pH solution (7.0) to simulate the saliva. For the low-pH solution, a soft drink (Sprite Zero ${ }^{\mathrm{TM}}$; Coca-Cola Co., Atlanta, GA, USA) was $\Xi$ used (13). For the neutral-pH solution, we used $1.5 \mathrm{mM}$ of calcium, $0.9 \mathrm{mM}$ of phosphate, $0.15 \mathrm{M}$ of potassium chloride, Tris buffer, and $0.05 \mu \mathrm{g}$ of fluoride $/ \mathrm{mL}$ (14).

All specimens were submitted to a three-day series of erosion cycles, performed with freshly opened bottles of Sprite Zero ${ }^{\mathrm{TM}}$ three times daily, for 5 minutes. After the erosion protocol, the specimens were rinsed in distilled and deionized water for five seconds and transferred to artificial saliva for two hours. After the last day of the erosive challenge, the specimens were also stored in artificial saliva overnight. The solutions were changed daily to avoid oversaturation and the experiment was carried out at $37^{\circ} \mathrm{C}$ (Fig. 1G).

\section{Analysis In Noncontact Three-Dimensional Profilometry}

Following removal of the nail varnish protection that covered half of the surfaces of the enamel blocks (i.e., the untreated areas), the topography of the blocks (including both the untreated and treated areas) was analyzed (Fig. 1H).

Measurement and capture blocks were performed using a noncontact 3D profilometer (Nanovea PS50 Optical; Nanovea Inc., Irvine, CA, USA). The parameters (chromatic confocal sensor with a white light axial, scan velocity of 2 $\mathrm{mm} / \mathrm{s}$, and refractive index of 10,000 ) used to analyze the values of Sa and TSL followed the same methodology of a recent author (15). The Sa value was calculated as $\mathrm{Sa}=$ Sa 1 - Sa2, where Sa 1 was the average of roughness in the untreated area and Sa2 was the average of roughness in the treated area, per block. TSL was established as the difference in height between said untreated and treated areas, per block. During calculation, three linear measurements were completed in triplicate. The examiner of the study was blind for the analyses. The same examiner only had access to the blocks using random numbers that were previously demarcated (Fig. 1).

\section{Analysis in Scanning Electron Microscopy}

Two blocks from each group were randomly assigned to undergo scanning electron microscopy (SEM) analysis. The blocks were covered with a thin layer of gold and analyzed by SEM (VEGA 3; TESCAN, Brno, the Czech Republic) at increased magnifications of $500 x$ and 2,000x. The photomicrographs obtained showed the microstructural characteristics of the treated and untreated areas (Fig. 1J).

\section{Statistical Analysis}

Data from Sa and TSL were assessed for normality. The Shapiro-Wilk test was applied to verify whether the data were normally distributed. One-way analysis of variance followed by Tukey's test were used to evaluate the Sa measurement, while the Kruskal-Wallis and Mann-Whitney $\mathrm{U}$ tests were used to complete the TSL analysis. SPSS software version was used for statistical analysis. The level of significance adopted in the inferential statistics was 95\% $(\alpha<0.05)$. The SEM findings were analyzed descriptively, which involved an evaluation of the changes found on the surface of the sample between before (untreated area) and after (treated area) treatment after erosive challenge.

\section{Results}

Data for Sa values (differences between untreated and treated areas) as well as those for TSL values among the groups are presented in Table 1.

Table 1. Mean \pm standard deviation / Median (minimum-maximum) of differences in volumetric roughness (Sa) and tooth structure loss (TSL) of enamel after application for each product and erosive challenge.

\begin{tabular}{|c|c|c|}
\hline & Sa (Sa2-Sa1) & TSL \\
\hline & Mean (SD) & Median (min - max) \\
\hline $\mathrm{Ca}^{2}+-\mathrm{MSNs}$ & $-0.20( \pm 0.29) \mathrm{a}$ & $12.03(8.28-14.78)$ bc \\
\hline CPP-ACP & $-0.50( \pm 0.66) \mathrm{a}$ & $20.48(9.39-21.67) \mathrm{ac}$ \\
\hline $\mathrm{CPP}-\mathrm{ACP} / \mathrm{F}$ & $-0.07( \pm 0.53) \mathrm{a}$ & $15.61(8.55-54.12) a b$ \\
\hline TiF4 & $-0.13( \pm 0.42)$ a & $12.17(6.65-20.43)$ bc \\
\hline $\mathrm{NaF}$ & $-0.08( \pm 0.22)$ a & $10.15(4.74-19.28) \mathrm{b}$ \\
\hline $\begin{array}{l}\text { Water (negative } \\
\text { control) }\end{array}$ & $-2.26( \pm 1.74) b$ & $37.96(18.88-49.45) \mathrm{a}$ \\
\hline
\end{tabular}

Different letters represent statistical difference $(\mathrm{p}<0.05)$. 


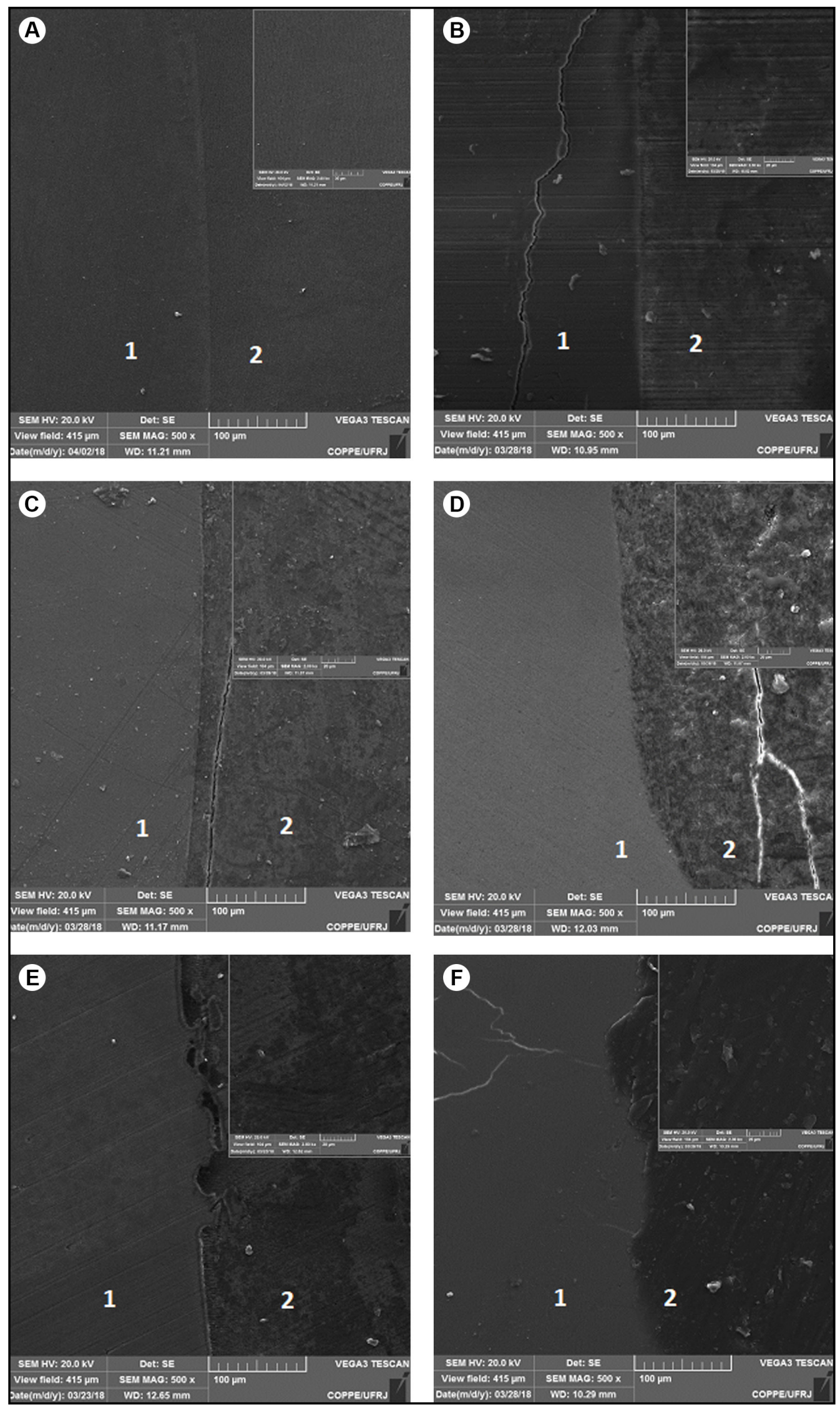

Figure 2: Surface SEM images of enamel samples before (untreated area) and after treatment and erosive challenge (treated area) in 500X (image of the interface: untreated and treated areas) and 2000x magnification (image of treated área in the upper right). (A) Ca ${ }^{2+-M S N}$, (B) CPP-ACP, (C) CPP-ACP/F- , (D) TiF4, (E) NaF, (F) Negative Control (Water). In the images: the number 1 represents the untreated and the number 2 represents the treated area. 
The control group demonstrated the worst Sa values, in a manner that was statistically different from the other groups $(p<0.05)$. When analyzing the $\mathrm{TSL}, \mathrm{NaF}_{1} \mathrm{Ca}^{2+}-\mathrm{MSNs}$, and $\mathrm{TiF}_{4}$ were statistically similar $(p=1.00)$ in regard to their results and displayed the shortest "step-down" between the treated and untreated areas, while the worst values of TSL were observed when Milli- ${ }^{\circledR}{ }^{\circledR}$ water was used (negative control), with results that were similar to those of CPP-ACP and CPP-ACP/F- $(p=0.05)$.

The SEM images of enamel samples before and after erosive challenge at $500 \times$ and 2,000 $\times$ magnifications (Fig. 2) revealed that the use of Milli- ${ }^{\circledR}{ }^{\circledR}$ water (negative control) led to the worst results (i.e., the greatest loss of tooth structure). This group also showed more porous enamel in comparison with the other groups, indicating a greater loss of tooth structure was present in the exposed area following the erosion process. Ultimately, the $\mathrm{NaF}_{1} \mathrm{Ca}^{2+}$ MSN, and $\mathrm{TiF}_{4}$ groups showed more effective protection against erosion than did the other groups, with less porosity as well as less mineral loss.

In Figure 3, a 3D profilometry scheme representation of samples reveals the topographic characteristics of the surface enamel at the end of the experiment (untreated and treated areas). A step of smaller size can be noticed qualitatively when one looks at the $3 \mathrm{~A}, 3 \mathrm{D}, 3 \mathrm{E}$ images, representing the occurrence of a greater degree of protection against erosion in the context of these products.

The same color scale between the groups represents a surface erosion standard, although the negative control has a higher TSL value.

\section{Discussion}

The objective of the present study was to compare the preventive effects observed while using a single application of experimental $\mathrm{Ca}^{2+}-\mathrm{MSN}$ with those of other products containing calcium and fluoride following submission to an erosive challenge. In our study, when analyzing TSL, despite not observing a significant statistical difference between the products tested, it was noted that some products-such as $\mathrm{Ca}^{2+}-\mathrm{MSNs}_{1} \mathrm{TiF}_{4}$, and $\mathrm{NaF}$-were more effective to prevent tooth enamel loss when compared with the control group. This finding is possibly explained by the fact that nanoparticles have an extensive area-volume relationship in $\mathrm{Ca}^{2+}-\mathrm{MSN}$ (10). In addition, silica has good biocompatibility and is characterized by its heightened resistance to abrasion mechanisms, high thermal stability, increased surface resistance, and capacity to reduce corrosion; it also includes a technology where the active compound is released slowly, allowing for more time on the surface (16). No other studies were found in the literature examining this new compound for the prevention of tooth erosion, showing the importance of our study.

Positive results were also obtained via the use of products containing fluoride, such as $\mathrm{NaF}$ and $\mathrm{TiF}_{4}$, with the benefit of the former potentially related to a great affinity for the calcium present in saliva to form calcium fluoride $\left(\mathrm{CaF}_{2}\right)$, which evokes a reservoir on the surface of enamel wherein these fluorapatite globules are the first to be dissolved after an acid attack $(17,18)$. Besides this, $\mathrm{TiF}_{4}$ forms an incorporated layer of titanium that protects against mineral loss in addition to ensuring a high fluoride
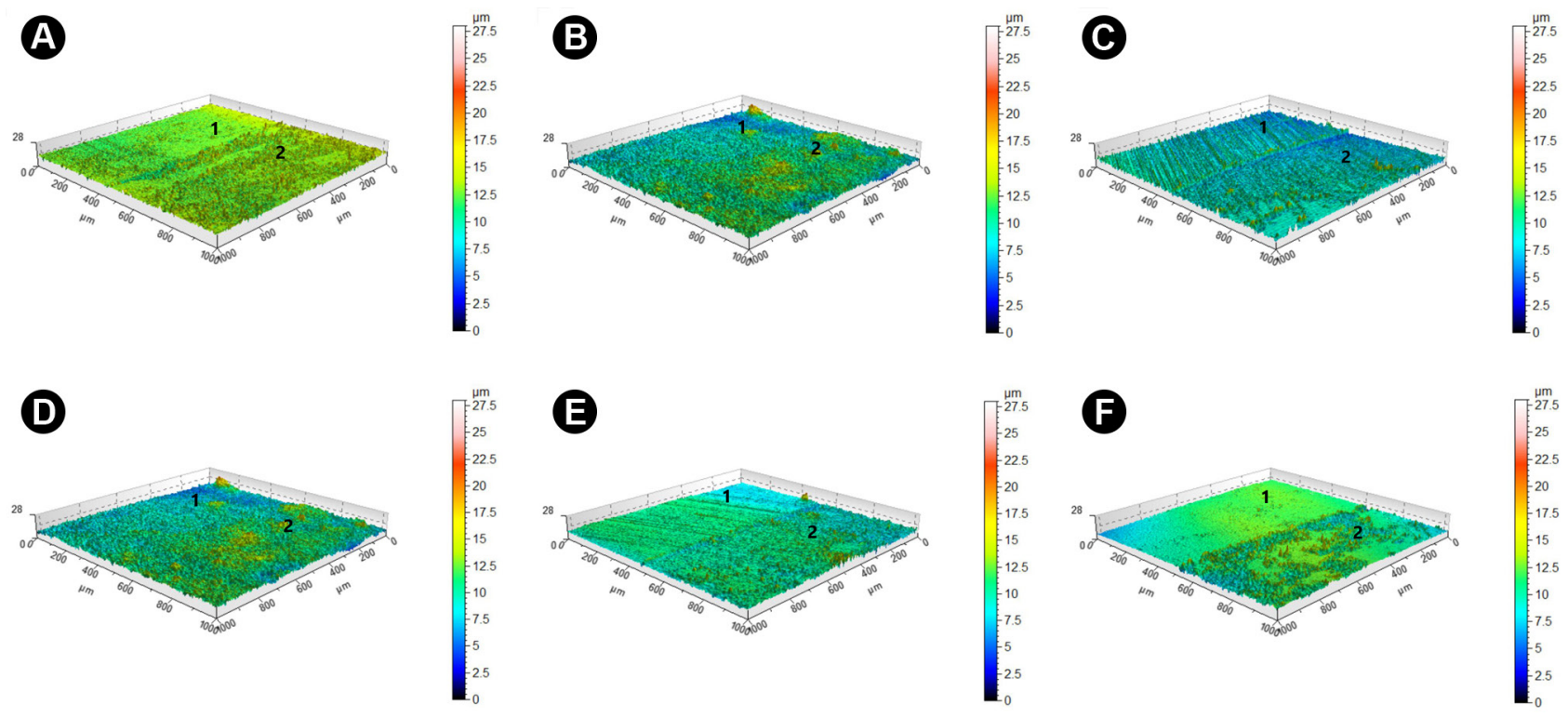

Figure 3: 3D profilometry scheme representation of samples before and after erosive challenge. (A) Ca²+-MSN, (B) CPP-ACP, (C) CPP-ACP/F- , (D) TiF4, (E) NaF, (F) Negative Control (Water). 1: untreated área; 2: treated área. In the color scale how much more for the blue color the greater the loss of surface structure. It is observed in the image the step formed by the loss of dental structure between areas 1 and 2. 
concentration (19). These results corroborate with those of Comar et al. (20), who correlated the occurrence of a lower structural loss with the use of $\mathrm{TiF}_{4}$ and $\mathrm{NaF}$ when compared with a negative control (Milli- $Q^{\circledR}$ water). Thus, in the present study, were obtained excellent results, with $\mathrm{Ca}^{2+}$-MSN representing a new and very beneficial compound when compared with products already used, such as $\mathrm{TiF}_{4}$ and $\mathrm{NaF}$.

In the present study, CPP-ACP and CPP-ACP/F- did not demonstrate significantly effective protection against TSL when compared with the other products considered. Interestingly, our findings in this regard were not similar to those of other research, such as that by de Reynolds et al. (8), who obtained satisfactory results with these products in comparison with fluorides. This may be explained by the fact that these products include a technology that increases their reserve of phosphate calcium ions in the supra gingival plaque (8), while, in the present study, we used simulated samples without dental biofilm and only introduced a dental erosion challenge. Furthermore, dental loss due to cariogenic challenge is less aggressive than that due to erosive challenge, and such may justify our results (21). Another important factor to be discussed is the CPP-ACP and CPPACP/F- application time. Studies that involved longer exposure times of three minutes to five minutes demonstrated better results than did ours, where only one minute of exposure was explored $(22,23)$. To our knowledge, there are no studies in existence comparing the time of application with the efficacy of CPP-ACP or CPP-ACP/F-; therefore, future studies are important as means to evaluate the difference between application times.

In addition, the use of calcium-based products with a fluoride addition, such as CPP-ACP/F-, did not present clearly satisfactory results when compared with other fluoride-based products in the present study. This fact could be explained by the possibility that the concentration of fluoride in the commercial product of CPP-ACP/F- is lower than that in the other products used.

The choice of the type of erosive cycle was based on previous studies $(13,24)$, who also used an acid beverage to simulate the effects of extrinsic acids in the production of erosive lesions. As performed by these earlier authors, a negative control group was used to validate the erosive cycle chosen and to compare the benefits of the products used in the present study. In our research, when we analyzed the value of $\mathrm{Sa}$, the findings of the negative control group were different from the other groups, showing the best values of roughness change. Although a false impression of being less rough based on the Sa analysis was given, when analyzing TSL values, it was observed that greater structural loss between the untreated area and the treated area occurred in the negative control group. Profilometry is the most indicated method for analysis of surface loss after the erosive challenge, since it does not destroy the surface being analyzed while allowing the user to evaluate the TSL measurement. This reveals the real loss between the analyzed areas, since it only analyzes the eroded area is not able to evaluate the actual loss of enamel (24). This is explained due to the mechanism of dental erosion causing a maceration on the surface of the tooth, which gives an appearance of softness and polishing when in a more advanced stage, which reflects on the smooth surface, despite having suffered a greater structural loss (25).

In summary, the present study aimed to simulate a clinical situation of a single application of fluoride and/or calcium compounds to prevent dental erosion in patients with possible ingestion of acidic drugs or a diet rich in acidic beverages, ultimately showing a great benefit regarding the prevention of erosion with products such as $\mathrm{Ca}^{2+}-\mathrm{MSNs}$, $\mathrm{NaF}_{1}$ and $\mathrm{TiF}_{4}$. In addition, these results provide a basis for future studies involving the same products for the treatment of already eroded teeth. It was concluded that the new compound tested ( $\mathrm{Ca}^{2+}$-MSNs) presented similarly satisfactory results as those of the most commonly used products such $\mathrm{TiF}_{4}$ and $\mathrm{NaF}$ in preventing TSL caused by erosive challenge.

\section{Resumo}

0 objetivo deste estudo foi comparar os efeitos de uma única aplicação de uma nova nanopartícula de sílica mesoporosa de cálcio ( $\left.\mathrm{Ca}^{2+}-\mathrm{MSN}\right)$ versus outros produtos à base de cálcio e / ou fluoreto contra a erosão dentária. Blocos de esmalte foram parcialmente cobertos e distribuídos em seis grupos ( $n=10)$ : $\mathrm{Ca}^{2+}-\mathrm{MSN}$; fosfopeptídeos de caseina/fosfato de cálcio amorfo (CPP-ACP); CPP-ACP / F- (900 ppm F-); tetrafluoreto de titânio $\left(\mathrm{TiF}_{4} 1 \%\right)$; fluoreto de sódio $(\mathrm{NaF} 1,36 \%)$; e água Milli- ${ }^{\circledR}$ (controle negativo). Uma única aplicação para cada produto foi realizada nas áreas expostas dos blocos e submetida a desafio erosivo. Diferenças na rugosidade volumétrica (Sa) e na perda de estrutura dentária (TSL) por meio de perfilometria tridimensional de não contato foram avaliadas. Microscopia eletrônica de varredura (MEV) foi realizada. Foram realizadas análise de variância e teste de Tukey para os testes Sa e Kruskal-Wallis e Mann-Whitney $(p<0,05)$ para $T S L$, respectivamente. Na avaliação de $\mathrm{Sa}$, todos os produtos apresentaram diferenças de rugosidade quando comparados ao grupo controle $(p<0,05)$, mas não entre si $(p>0,05)$. No entanto, ao analisar o TSL, observou-se que $\mathrm{Ca}^{2+}-\mathrm{MSNs}_{1} \mathrm{TiF}_{4}$ e NaF foram mais eficazes na prevenção da erosão dental versus CPP-ACP, CPPACP / F- e Milli- $Q^{\circledR}(p<0,05)$. Nas imagens de MEV, o controle negativo apresentou a pior perda de estrutura dentária, com o esmalte mais poroso. $\mathrm{A} \mathrm{Ca}^{2+}-\mathrm{MSN}$ foi tão eficaz quanto o $\mathrm{TiF}_{4}$ e o $\mathrm{NaF}$ para reduzir a perda da estrutura dentária.

\section{Acknowledgements}

This study was financed in part by the Coordenação de Aperfeiçoamento de Pessoal de Nivel Superior- Brasil- (CAPES) -Finance code 001.This study is part of the masters' stage of the first author. The authors also thank FAPERJ (E-26/202.924/2017) and CNPQ (303535/2016-4) for the financial support.

\section{References}

1. Ganss $C$. Definition of erosion and links to tooth wear. Monogr Oral Sci 
2006;20:9-16.

2. Wang $X$, Lussi A. Assessment and management of dental erosion. Dental Clinics 2010;54:565-578.

3. Shellis RP, Featherstone JD, Lussi A. Understanding the chemistry of dental erosion. Monogr Oral Sci 2014;25:163-179.

4. Lussi A, Jaeggi T. Chemical factors. Monogr Oral Sci 2006;20:77-87.

5. Yu H, Attin T, Wiegand A, Buchalla W. Effects of various fluoride solutions on enamel erosion in vitro. Caries Res 2010;44:390-401.

6. Newbrun E. What we know and do not know about fluoride. J Public Health Dent 2010;70:227-233.

7. Schlueter N, Ganss C, Mueller U, Klimek J. Effect of titanium tetrafluoride and sodium fluoride on erosion progression in enamel and dentine in vitro. Caries Res 2007;41:141-145.

8. Reynolds E. Casein phosphopeptide-amorphous calcium phosphate: the scientific evidence. Adv Dent Res 2009;21:25-29.

9. González-Vidal N, Muñoz-Guerra S, de Ilarduya AM, Benali S, Peeterbroeck S, Dubois P. Poly (hexamethylene terephthalate)-layered silicate nanocomposites. Eur polym J 2010;46:156-164.

10. Slowing II, Vivero-Escoto JL, Wu C-W, Lin VS-Y. Mesoporous silica nanoparticles as controlled release drug delivery and gene transfection carriers. Adv Drug Deliv Rev 2008;60:1278-1288.

11. Alexandria AK, Valença AMG, Cabral LM, Maia LC. Fluoride Varnishes against Dental Erosion Caused by Soft Drink Combined with Pediatric Liquid Medicine. Braz Dent J 2017;28:482-488.

12. Queiroz CS, Hara AT, Paes Leme AF, Cury JA. pH-cycling models to evaluate the effect of low fluoride dentifrice on enamel de-and remineralization. Braz Dent J 2008;19:21-27.

13. Magalhães $A C$, Levy FM, Rios D, Buzalaf MAR. Effect of a single application of $\mathrm{TiF}_{4}$ and $\mathrm{NaF}$ varnishes and solutions on dentin erosion in vitro. J Dent 2010;38):153-157.

14. Nassur C, Pomarico L, de Sousa VP, Cabral LM, Maia LC. Characterization of a new TiF4 and $\beta$-cyclodextrin inclusion complex and its in vitro evaluation on inhibiting enamel demineralization. Arch Oral Biol 2013;58):239-247.

15. Alexandria AK, Meckelburg NdA, Puetter UT, Salles JT, Souza IPR, Maia LC. Do pediatric medicines induce topographic changes in dental enamel? Braz Oral Res 2016;30: e11

16. Tang F, Li L, Chen D. Mesoporous silica nanoparticles: synthesis, biocompatibility and drug delivery. Adv Mater 2012;24:1504-1534.

17. Algarni $A$, Mussi $M$, Moffa $E$, Lippert $F$, Zero $D$, Siqueira $W$, et al The impact of stannous, fluoride ions and its combination on enamel pellicle proteome and dental erosion prevention. PloS one. 2015;10):e0128196.

18. Wegehaupt F, Attin T. The role of fluoride and casein phosphopeptide/ amorphous calcium phosphate in the prevention of erosive/abrasive wear in an in vitro model using hydrochloric acid. Caries Res 2010;44:358-363.

19. Wiegand $A$, Magalhães $A C$, Attin T. Is Titanium Tetrafluoride $\left(\mathrm{TiF}_{4}\right)$ Effective to Prevent Carious and Erosive Lesions? A Review of the Literature. Oral Health Prev Dent 2010;8:159-64.

20. Comar LP, Cardoso CDAB, Charone S, Grizzo LT, Buzalaf MAR, Magalhaes $\mathrm{AC} \mathrm{TiF}_{4}$ and $\mathrm{NaF}$ varnishes as anti-erosive agents on enamel and dentin erosion progression in vitro. J Appl Oral Sci 2015;23:14-18.

21. Salas C, Guglielmi C, Raggio D, Mendes F. Mineral loss on adjacent enamel glass ionomer cements restorations after cariogenic and erosive challenges. Arch oral Biol 2011;56:1014-1019.

22. Somani R, Jaidka S, Singh DJ, Arora V. Remineralizing potential of various agents on dental erosion. J Oral Biol Craniofac Res 2014;4:104108.

23. Carvalho FGD, Brasil VLM, Silva Filho TJD, Carlo HL, Santos RLD, Lima BASGD. Protective effect of calcium nanophosphate and CPP-ACP agents on enamel erosion. Braz Oral Res 2013;27:463-470

24. Alexandria AK, Vieira $\mathrm{TI}$, Pithon $M M$, da Silva Fidalgo TK, FonsecaGoncalves A, Valenca AM, et al. In vitro enamel erosion and abrasioninhibiting effect of different fluoride varnishes. Arch Oral Biol 2017;77:39-43.

25. West NX, Joiner A. Enamel mineral loss. J Dent 2014;42:S2-S11.

Received June 6, 2019

Accepted October 14, 2019 